\title{
The farnesyltransferase inhibitor, FTI-2153, inhibits bipolar spindle formation during mitosis independently of transformation and Ras and p53 mutation status
}

\author{
NC Crespo ${ }^{1,2}$, F Delarue ${ }^{1,2}$, J Ohkanda ${ }^{3}$, D Carrico ${ }^{3}$, \\ AD Hamilton ${ }^{3}$ and SM Sebti ${ }^{*, 1,2}$ \\ ${ }^{1}$ Department of Oncology, Drug Discovery Program, H. Lee Moffitt Cancer \\ Center and Research Institute, University of South Florida, Tampa, Florida, \\ USA \\ 2 Department of Biochemistry \& Molecular Biology, University of South Florida, \\ Tampa, Florida, USA \\ ${ }^{3}$ Department of Chemistry, Yale University, New Haven, Connecticut, USA \\ * Corresponding author: SM Sebti, Director, Drug Discovery Program, H. Lee \\ Moffitt Cancer Center \& Research Institute, 12902 Magnolia Drive, MRC- \\ DRDIS, Tampa, FL 33612, USA. Tel: (813) 979-6734; Fax: (813) 979-6748; \\ E-mail: sebti@moffitt.usf.edu
}

Received 1.10.01; revised 18.12.01; accepted 8.1.02 Edited by B Osborne

\begin{abstract}
Recently, we have shown that the farnesyltransferase inhibitor FTI-2153 induces accumulation of two human lung cancer cell lines in mitosis by inhibiting bipolar spindle formation during prometaphase. Here we investigate whether this mitotic arrest depends on transformation, Ras and/or p53 mutation status. Using DAPI staining (DNA) and immunocytochemistry (microtubules), we demonstrate that in normal primary foreskin fibroblasts (HFF), as well as in several cancer cell lines of different origins including human ovarian (OVCAR3), lung (A-549 and Calu-1) and fibrosarcoma (HT1080), FTI-2153 inhibits bipolar spindle formation and induces a rosette morphology with a monopolar spindle surrounded by chromosomes. In both malignant cancer cell lines and normal primary fibroblasts, the percentage of prometaphase cells with bipolar spindles decreases from $67-92 \%$ in control cells to $2-28 \%$ in FTI2153 treated cells. This inhibition of bipolar spindle formation correlates with an accumulation of cells in prometaphase. The ability of FTI-2153 to inhibit bipolar spindle formation is not dependent on p53 mutation status since both wild-type (HFF, HT1080 and A-549) and mutant (Calu-1 and OVCAR3) p53 cells were equally affected. Similarly, both wild-type (HFF and OVCAR3) and mutant (HT1080, Calu-1 and A-549) Ras cells accumulate monopolar spindles following treatment with FTI-2153. However, two cell lines, NIH3T3 (WT Ras and WT p53) and the human bladder cancer cell line, T-24 (mutant H-Ras and mutant p53) are highly resistant to FTl-2153 inhibition of bipolar spindle formation. Finally, the ability of FTI-2153 to inhibit tumor cell proliferation does not correlate with inhibition of bipolar spindle formation. Taken together these results
\end{abstract}

demonstrate that the ability of FTI-2153 to inhibit bipolar spindle formation and accumulate cells in mitosis is not dependent on transformation, Ras or p53 mutation status. Furthermore, in some cell lines, FTls inhibit growth by mechanisms other than interfering with the prophase/ metaphase traverse.

Cell Death and Differentiation (2002) 9, 702-709. doi:10.1038/ sj.cdd. 4401023

Keywords: FTase; FTIs; mitosis; bipolar spindles; Ras; p53

Abbreviations: $\mathrm{CAAX}, \mathrm{C}=$ cysteine, $\mathrm{A}=$ aliphatic amino acid $\mathrm{X}=$ any amino acid; FTase, farnesyltransferase; FTI, farnesyltransferase inhibitor; GGTase, geranylgeranyltransferase; HFF, human foreskin fibroblasts

\section{Introduction}

Protein farnesyltransferase (FTase) catalyzes the covalent attachment of the lipid farnesyl to the cysteine sulfhydryl of proteins that terminate at their carboxyl terminus with the consensus sequence $\mathrm{CAAX}(\mathrm{C}=$ cysteine, $\mathrm{A}=$ aliphatic amino acid, $\mathrm{X}=$ methionine, serine, alanine, glutamic acid or cysteine) (reviewed in Zhang and Casey). ${ }^{1}$ Because farnesylation was shown to be required for the malignant transforming activity of the oncoprotein Ras, FTase inhibitors (FTIs) were developed as potential anticancer drugs. ${ }^{2-4}$ In vitro, FTls are highly potent and selective for FTase over the closely related family member, protein geranylgeranyltransferase-I (GGTase I). ${ }^{2}$ In cultured cells, FTls inhibit the growth of transformed cells selectively over non-transformed cells. ${ }^{5,6}$ Furthermore, FTIs are very effective at inhibiting the growth of a range of human cancer cell lines in soft agar as well as in nude mouse xenografts. ${ }^{7-13}$ This tumor growth inhibition does not depend on the Ras mutation status and several lines of evidence suggest that other farnesylated proteins, in addition to Ras, may be critical targets for FTIs' mechanism of action. ${ }^{9,13} \mathrm{FTIs}$ are also highly effective at inducing tumor regression in transgenic animal models. ${ }^{14-17}$ Because of their outstanding antitumor activity and lack of toxicity in animal models, FTIs have rapidly entered human clinical trials and some are in phase III. ${ }^{18,19}$

Although major milestones have been reached in the use of FTls to treat cancer, the mechanism of their antitumor activity is still not known, in part because of about 50 known potential substrates for FTase. Therefore, depending on which farnesylated proteins are expressed within a cancer cell and contribute to its malignancy as well as the genetic background of the cell, FTIs may or may not be effective. Furthermore, in those cellular environments 
where FTIs are effective, the mechanisms by which they inhibit tumor cell growth may be different. Consistent with this are our previous cell cycle studies in a panel of human cancer cell lines, that showed that FTIs either induce a G0/ G1 phase accumulation, a G2/M phase accumulation or have no effect on cell cycle distribution. ${ }^{20}$ Recently, we $e^{21}$ and others ${ }^{22}$ have focused on understanding the mechanism by which FTls induce G2/M accumulation. In two human cancer cell lines where FTIs induce G2/M accumulation, we found that FTIs inhibit bipolar spindle formation and prevent chromosome alignment, thus accumulating cells at prometaphase during mitosis. ${ }^{21}$ This suggested that a farnesylated protein plays a pivotal role in the regulation of the transition from prophase to metaphase. However, these studies were performed with two human lung cancer cell lines only and whether the requirement for farnesylated proteins for prophase/metaphase transition applies to other cancer cell lines with different genetic alterations is not known. Furthermore, normal cells are known to be relatively insensitive to FTIs. Therefore, it is also important to determine whether FTIs inhibit bipolar spindle formation in non-transformed cells. In this manuscript, we report the use of a panel of human cancer cell lines, human primary foreskin fibroblasts and the immortalized cell line NIH3T3 to address these important questions.

\section{Results}

Recently, we have shown that FTI-2153 inhibits bipolar spindle formation in two human lung cancer cell lines suggesting that farnesylated proteins are required for the prophase/metaphase transition. In this manuscript we have expanded these studies to other cell lines to investigate the importance of the Ras and p53 mutation status as well as whether non-transformed cells also require farnesylated proteins for bipolar spindle formation. To this end, we have used a panel of human cancer cell lines, human primary fibroblasts and NIH3T3 cells. Table 1 lists the cells used as the human cancer cell lines OVCAR3 (ovarian), T-24 (bladder), HT1080 (fibrosarcoma), the two human lung adenocarcinoma cell lines, A-549 and Calu-1 (that were used in the previous study), NIH3T3 cells (immortalized murine fibroblasts) and HFF (human foreskin primary fibroblasts).

Table 1

\begin{tabular}{|c|c|c|c|}
\hline Cell line & Tissue type & Ras status & p53 status \\
\hline NIH3T3 & $\begin{array}{l}\text { Immortalized mouse } \\
\text { fibroblasts }\end{array}$ & WT & WT \\
\hline HFF & $\begin{array}{l}\text { Primary human } \\
\text { foreskin fibroblasts }\end{array}$ & WT & WT \\
\hline HT1080 & Human fibrosarcoma & mutant N-Ras & WT \\
\hline $\mathrm{T}-24$ & Human bladder carcinoma & mutant H-Ras & mutant \\
\hline $\begin{array}{l}\text { OVCAR3 } \\
\text { A-549 }\end{array}$ & $\begin{array}{c}\text { Human ovarian carcinoma } \\
\text { Human lung } \\
\text { adenocarcinoma }\end{array}$ & $\begin{array}{c}\text { WT } \\
\text { mutant K-Ras }\end{array}$ & $\begin{array}{l}\text { mutant } \\
\text { WT }\end{array}$ \\
\hline Calu-1 & $\begin{array}{l}\text { Human lung } \\
\text { adenocarcinoma }\end{array}$ & mutant K-Ras & deleted \\
\hline
\end{tabular}

WT, wild-type

\section{Effects of FTl-2153 treatment on progression through mitosis}

The different cell lines (Table 1) were treated for $48 \mathrm{~h}$ with FTI2153 and processed with DAPI staining to visualize the DNA and anti- $\alpha$-tubulin antibody to immunolocalize microtubules, as described under Materials and Methods. First we determined the effect of $\mathrm{FTI}-2153$ on progression through various phase of mitosis. Figure 1 shows control, non-treated A-549 cells undergoing cell division by traversing the various mitotic phases which were defined as follows: prophase/ prometaphase cells have condensed chromatin that was not yet aligned on the metaphase plate, metaphase cells have the chromosomes aligned on the central axis between the two poles, anaphase cells have their chromosome being pulled toward the poles and telophase/cytokinesis cells have the DNA at the poles and are pinched at the central axis (Figure 1). When A-549 cells were treated with FTI-2153 $(15 \mu \mathrm{M}$ for $48 \mathrm{~h})$, the proportion of cells at prometaphase increased relative to the other phases of mitosis. Furthermore, FTI-2153
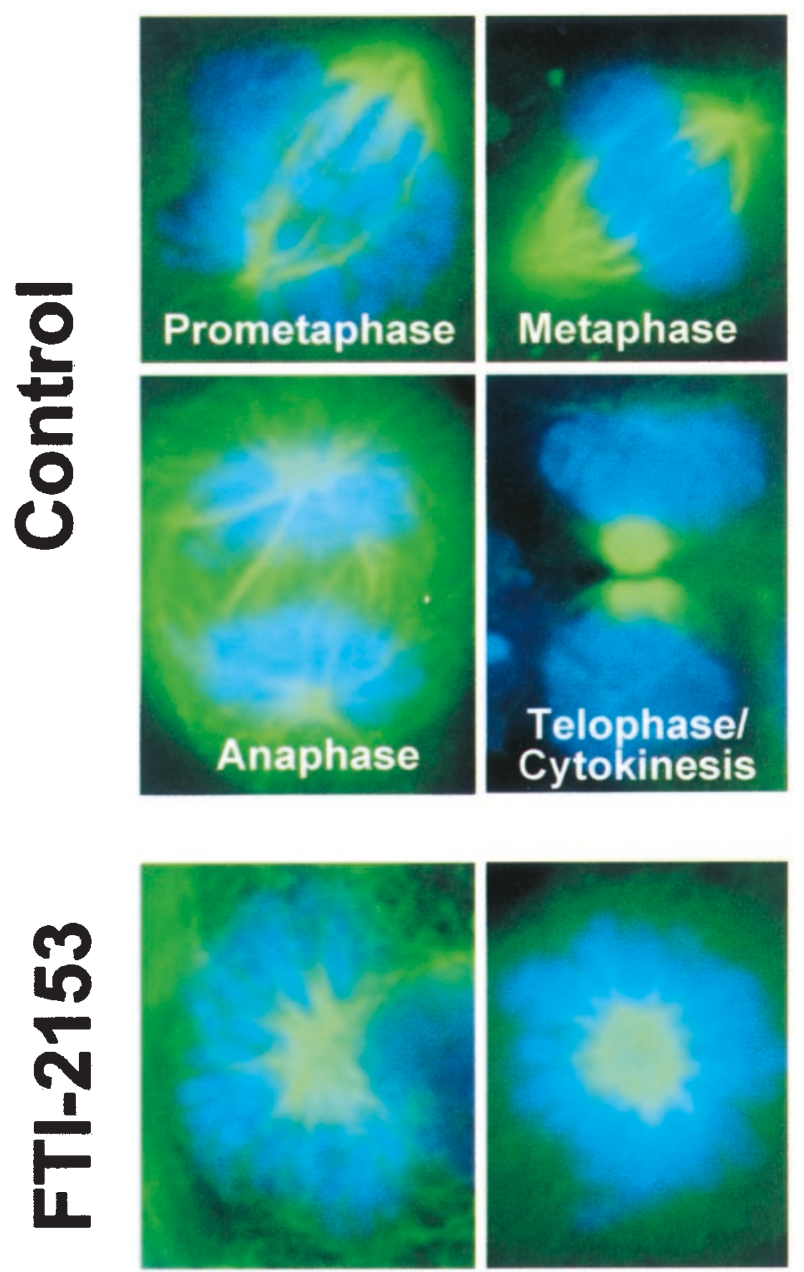

Figure $1 \mathrm{FTI}-2153$ induces accumulation of a rosette-like chromatin/ microtubule morphology during mitosis. A-549 cells were treated with either vehicle (control) or FTI-2153 $(15 \mu \mathrm{M}, 48 \mathrm{~h})$ and the cells were stained with DAPI to mark the DNA (blue) and with an antibody against $\alpha$-tubulin to label microtubules (green) as described in Materials and Methods 
accumulated cells at prometaphase with a rosette-like morphology where chromosomes form a ring surrounding a monoaster of microtubules (Figure 1). We next quantitated the effects of FTI-2153 on mitotic phase distribution in various cell lines. Figure 2 shows that in all cells, except for T-24 and NIH3T3, FTI-2153 treatment increased the proportion of mitotic cells in prometaphase and decreased the percentage of cells in telophase/cytokinesis. For example, in HT1080 cells, the percentage of cells in prometaphase and telophase/ cytokinesis were 5 and $85 \%$ in control cells and 55 and $35 \%$ in FTI-2153-treated cells, respectively. Similarly, in HFF cells the percentages changed from 10 and $85 \%$ in control cells to 60 and $30 \%$ in FTI-2153-treated cells. Calu-1 and A-549 cells, as described previously, had similarly large changes (from 15.6 and $35 \%$ to 55.7 and $17 \%$ in Calu- 1 cells and from 2.4 and $78.9 \%$ to 45.9 and $37.8 \%$ in A-549 cells), whereas OVCAR3 had smaller changes (from 33 and $42 \%$ to 56 and $26 \%$ ). In contrast, FTI-2153 did not significantly affect the distribution of the different phases of mitosis in T-24 and NIH3T3 cells (Figure 2).

\section{FTI-2153 inhibits bipolar spindle formation in normal and malignant cells regardless of their Ras and p53 mutation status}

The FTI-2153-induced prometaphase accumulation suggested that FTls affect a step in mitosis that is critical to

\section{Mitotic Figure Distribution}
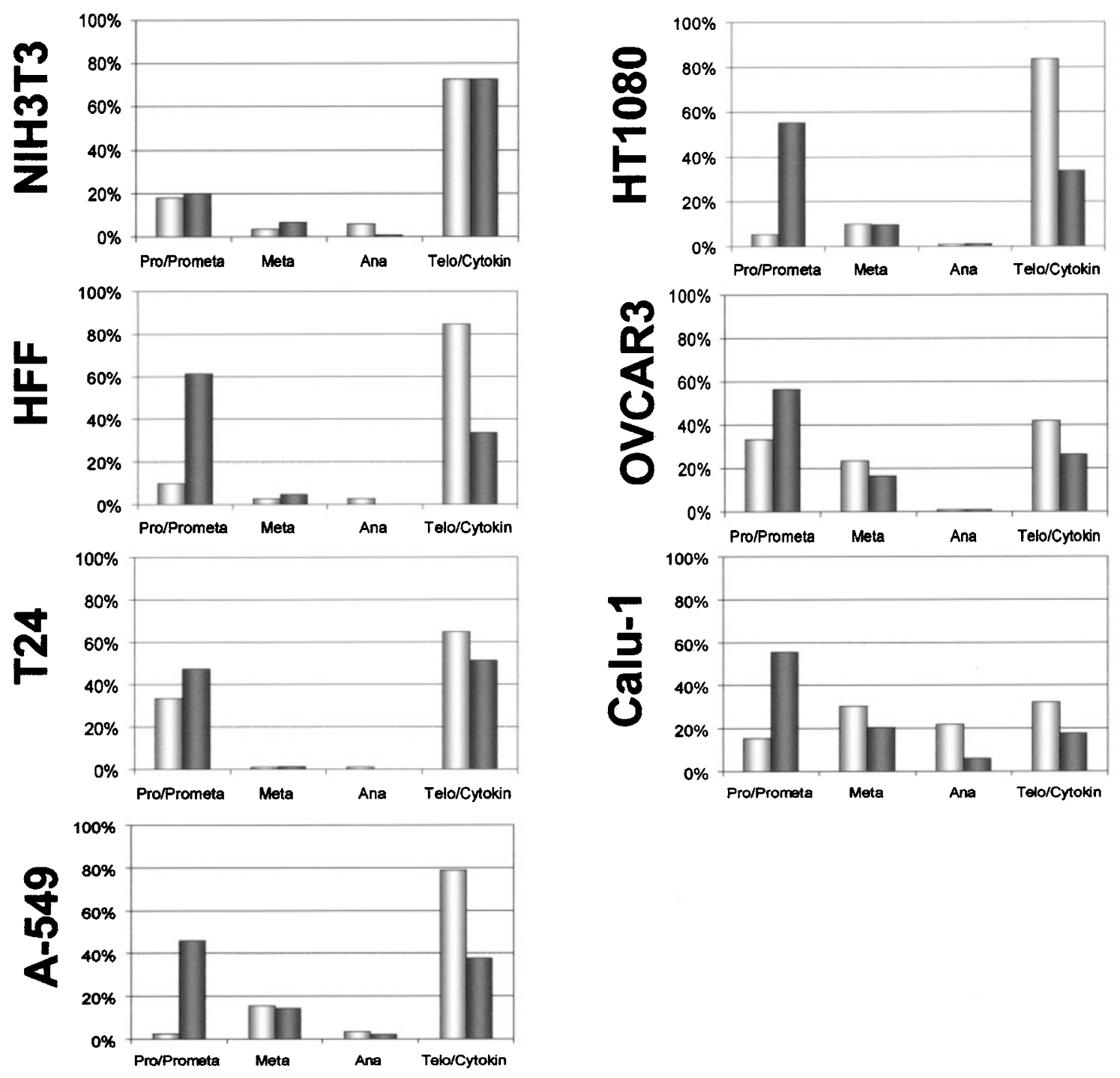

Figure 2 FTI-2153 accumulates cells in prometaphase independently of transformation, Ras and p53 mutation status. Asynchronous populations of cells were treated with $15 \mu \mathrm{M} \mathrm{FTI-2153.} \mathrm{After} 72 \mathrm{~h}$, cells were stained as described for Figure 1 and at least 50 mitotic figures for each cell type were counted and categorized as prophase/prometaphase, metaphase, anaphase or telophase/cytokinesis. Control cells are indicated as white bars and FTI-treated cells are indicated as gray bars 
reaching metaphase. In order for cells to reach metaphase, centrosomes must separate to form bipolar spindles prior to chromosome alignment at the metaphase plate. We therefore determined whether FTI-2153 affects bipolar spindle formation and chromatin morphology. To this end, the various cells of Table 1 were treated with $\mathrm{FTI}-2153$ as described for Figures 1 and 2 and the number of cells with monoasters $v s$ those with diasters were counted. The percentages of the prometaphase cells with monoasters vs diasters were reported as mean \pm S.D. of three independent experiments except for OVCAR3, A-549 and Calu-1 cells. In each experiment at least 50 prometaphase cells were counted. Figure 3 shows that in HT1080 cells, the percentage of prometaphase cells with a monoaster increased from $8.0 \pm 7.9 \%$ in control cells to $71.4 \pm 18.6 \%$ in FTI-2153-treated cells. In these cells, the percentage with diasters decreased from $92.0 \pm 7.9$ to $28.6 \pm 18.6 \%$ upon FTI-2153 treatment. In HFF cells the percentage of prometaphase cells with diasters decreased from $75.2 \pm 10.1$ to $26.1 \pm 20.4 \%$. Figure 3 also shows that in OVCAR3 the percentage of cells with diasters decreased from 73.6 to $20.4 \%$. In A-549 cells the decrease was from 81.5 to $34.0 \%$ and in Calu-1 cells the decrease was from 95 to $0 \%$. In contrast, the percentage of prometaphase cells with diasters was not affected by FTI-2153 treatment in NIH3T3 (from $83.2 \pm 3.4$ to $72.9 \pm 10.3 \%$ ) and T-24 cells (from $76.7 \pm 18.5$ to $75.7 \pm 8.6 \%$ ). These results clearly demonstrate that the ability of FTI-2153 to inhibit bipolar spindle formation is independent of whether the cell is transformed, of tissue of origin, and of Ras and p53 mutation status.

\section{FTI-2153 increases the percentage of} prometaphase cells with ring-like DNA morphology in transformed and non-transformed cells

The ability of FTI-2153 to inhibit bipolar spindle formation is also accompanied by a rosette-like morphology where

\section{Bipolar Spindle Formation}

\begin{tabular}{|c|c|c|c|}
\hline \multirow[b]{2}{*}{ Cell Line } & \multirow[b]{2}{*}{ Sample } & \multicolumn{2}{|c|}{ Average } \\
\hline & & & \\
\hline \multirow{2}{*}{ NH3T3 } & Control & $83.2 \pm 3.4 \%$ & $16.8 \pm 3.4 \%$ \\
\hline & FTI-2153 & $72.9 \pm 10.3 \%$ & $27.1 \pm 10.3 \%$ \\
\hline \multirow{2}{*}{ HFF } & Control & $75.2 \pm 10.1 \%$ & $24.8 \pm 10.1 \%$ \\
\hline & FTI-2153 & $26.1 \pm 20.4 \%$ & $73.8 \pm 20.4 \%$ \\
\hline \multirow{2}{*}{ HT1080 } & Control & $92.0 \pm 7.9 \%$ & $8.0 \pm 7.9 \%$ \\
\hline & \begin{tabular}{|l|} 
FTI-2153 \\
\end{tabular} & $28.6 \pm 18.6 \%$ & $71.4 \pm 18.6 \%$ \\
\hline \multirow{2}{*}{ T24 } & Control & $76.7 \pm 18.5 \%$ & $23.3 \pm 18.5 \%$ \\
\hline & \begin{tabular}{|l|} 
FTI-2153 \\
\end{tabular} & $75.7 \pm 8.6 \%$ & $24.2 \pm 8.6 \%$ \\
\hline \multirow{2}{*}{ OVCAR3 } & Control & $73.6 \%$ & $26.4 \%$ \\
\hline & FTI-2153 & $20.4 \%$ & $79.7 \%$ \\
\hline \multirow{2}{*}{ A-549 } & Control & $81.5 \%$ & $18.5 \%$ \\
\hline & FTI-2153 & $34.0 \%$ & $66.0 \%$ \\
\hline \multirow{2}{*}{ Calu-1 } & Control & $95.00 \%$ & $5.00 \%$ \\
\hline & FTI-2153 & $0.00 \%$ & $100.00 \%$ \\
\hline
\end{tabular}

Figure $3 \mathrm{FTI}-2153$ inhibits bipolar spindle formation independently of transformation, Ras and p53 mutation status. Asynchronous populations of cells were treated with $15 \mu \mathrm{M} \mathrm{FTI}-2153$. After $72 \mathrm{~h}$, cells were stained with an antibody against $\alpha$-tubulin to mark the microtubules. At least 50 prometaphase cells were counted and analyzed for bipolar spindle formation 
the monoaster is surrounded by a ring of chromosomes. To determine if accumulation of prometaphase cells with ring chromosome morphology is also independent of transformation as well as Ras and p53 mutation status, the cells in Table 1 were processed as described above for Figures 1 and 2. Figure 4 shows that in HT1080 cells the percentage of cells with ring-like DNA morphology increased from $15.4 \pm 12.2$ to $66.3 \pm 9.7 \%$ upon $\mathrm{FTI}-2153$ treatment. This percentage increased from $22.5 \pm 11.0$ to $69.9 \pm 11.7 \%$ in HFF cells, from 19.3 to $48.9 \%$ in OVCAR3 cells, from 28.6 to $85 \%$ in Calu-1 cells and from 20.7 to $75.7 \%$ in A-549 cells. In contrast, in T-24 cells $(20.2 \pm 19.9$ to $24.7 \pm 9.2 \%)$ and NIH3T3 cells $(22.0 \pm 9.3$ to $29.7 \pm 12.6 \%)$ FTI-2153 had little effect on the percentage of cells with ring-like chromatin morphology.
The ability of FTI-2153 to inhibit tumor cell proliferation is independent of its ability to inhibit bipolar spindle formation

We next determined whether there is a correlation between FTI-2153 inhibition of tumor cell growth and inhibition of bipolar spindle formation. To this end, NIH3T3, HFF, HT1080, A-549, OVCAR3, T-24 and Calu-1 cells were treated in 96well plates with various concentrations of FTI-2153 (0$50 \mu \mathrm{M})$ for $48 \mathrm{~h}$. Inhibition of tumor cell proliferation was assessed by MTT assay as described under Materials and Methods. Figure 5 shows that some cell lines are relatively resistant to FTI-2153 (NIH3T3, HFF and HT-1080), others are more sensitive (T-24 and Calu-1) and some are in between (A-549 and OVCAR3). At $15 \mu \mathrm{M}, \mathrm{FTI}-2153$ inhibited T-24 and Calu-1 cell growth by 38 and $36 \%$, respectively. In contrast,

\section{DNA Morphology}

\begin{tabular}{|c|c|c|c|}
\hline \multirow[b]{2}{*}{ Cell Line } & \multirow[b]{2}{*}{ Sample } & \multicolumn{2}{|c|}{ Average } \\
\hline & & & \\
\hline \multirow{2}{*}{ NIH3T3 } & \multirow{2}{*}{\begin{tabular}{|c|} 
Control \\
FTI-2153 \\
\end{tabular}} & $78.0 \% \pm 9.3$ & $22.0 \% \pm 9.3$ \\
\hline & & $70.3 \% \pm 12.6$ & $29.7 \% \pm 12.6$ \\
\hline \multirow{2}{*}{ HFF } & Control & $77.5 \% \pm 11.0$ & $22.5 \% \pm 11.0$ \\
\hline & \begin{tabular}{|l|} 
FTI-2153 \\
\end{tabular} & $30.1 \% \pm 11.7$ & $69.9 \% \pm 11.7$ \\
\hline \multirow{2}{*}{ HT1080 } & Control & $84.6 \% \pm 12.2$ & $15.4 \% \pm 12.2$ \\
\hline & FTI-2153 & $33.7 \% \pm 9.7$ & $66.3 \% \pm 9.7$ \\
\hline \multirow{2}{*}{ T24 } & Control & $79.8 \% \pm 19.9$ & $20.2 \% \pm 19.9$ \\
\hline & FTI-2153 & $75.3 \% \pm 9.2$ & $24.7 \% \pm 9.2$ \\
\hline \multirow{2}{*}{ OVCAR3 } & \multirow{2}{*}{\begin{tabular}{|c|} 
Control \\
FTI-2153 \\
\end{tabular}} & $80.8 \%$ & $19.3 \%$ \\
\hline & & $51.1 \%$ & $48.9 \%$ \\
\hline \multirow{2}{*}{ A-549 } & \multirow{2}{*}{\begin{tabular}{|c|} 
Control \\
FTI-2153 \\
\end{tabular}} & $79.3 \%$ & $20.7 \%$ \\
\hline & & $24.3 \%$ & $75.7 \%$ \\
\hline \multirow{2}{*}{ Calu-1 } & \multirow{2}{*}{\begin{tabular}{|c|} 
Control \\
FTI-2153
\end{tabular}} & $71.4 \%$ & $28.6 \%$ \\
\hline & & $15.0 \%$ & $85.0 \%$ \\
\hline
\end{tabular}

Figure 4 FTI-2153 induces a ring-like chromatin structure independently of transformation, Ras and p53 mutation status. Asynchronous populations of cells were treated with $15 \mu \mathrm{M} \mathrm{FTI-2153}$. After $72 \mathrm{~h}$, cells were stained with DAPI to mark the DNA. At least 50 prometaphase cells were counted and analyzed for ring-like chromatin morphology 
NIH3T3, HFF and HT-1080 were less sensitive and were inhibited by only 8,8 and $13 \%$, respectively. A-549 and OVCAR3 cell growth was inhibited by 25 and $22 \%$, respectively. Thus, even though T-24 and Calu-1 cells are equisensitive to FTI-2153 cell growth inhibition, FTI-2153 inhibits bipolar spindle formation only in Calu-1 cells (Figure 3). Similarly, HFF and NIH3T3 cells are both resistant to FTI2153 growth inhibition (Figure 5), yet only NIH3T3 cells are resistant to FTI-2153 inhibition of bipolar spindle formation (Figure 3).

\section{Discussion}

We have investigated whether the ability of FTI-2153 to inhibit bipolar spindle formation and induce mitotic arrest depends on transformation, and/or Ras and p53 mutation status. Because FTIs are relatively non-toxic to normal cells, a key issue is whether FTIs have similar effects on non-transformed immortalized cells and normal primary cells. Furthermore, a critical question concerns the inhibition of bipolar spindle formation and its dependency on key genetic aberrations associated with malignant transformation, such as Ras and p53 deletion/mutation status. Using a panel of human cancer cell lines of different tissue origins and with different genetic alterations, a normal primary foreskin fibroblast and the
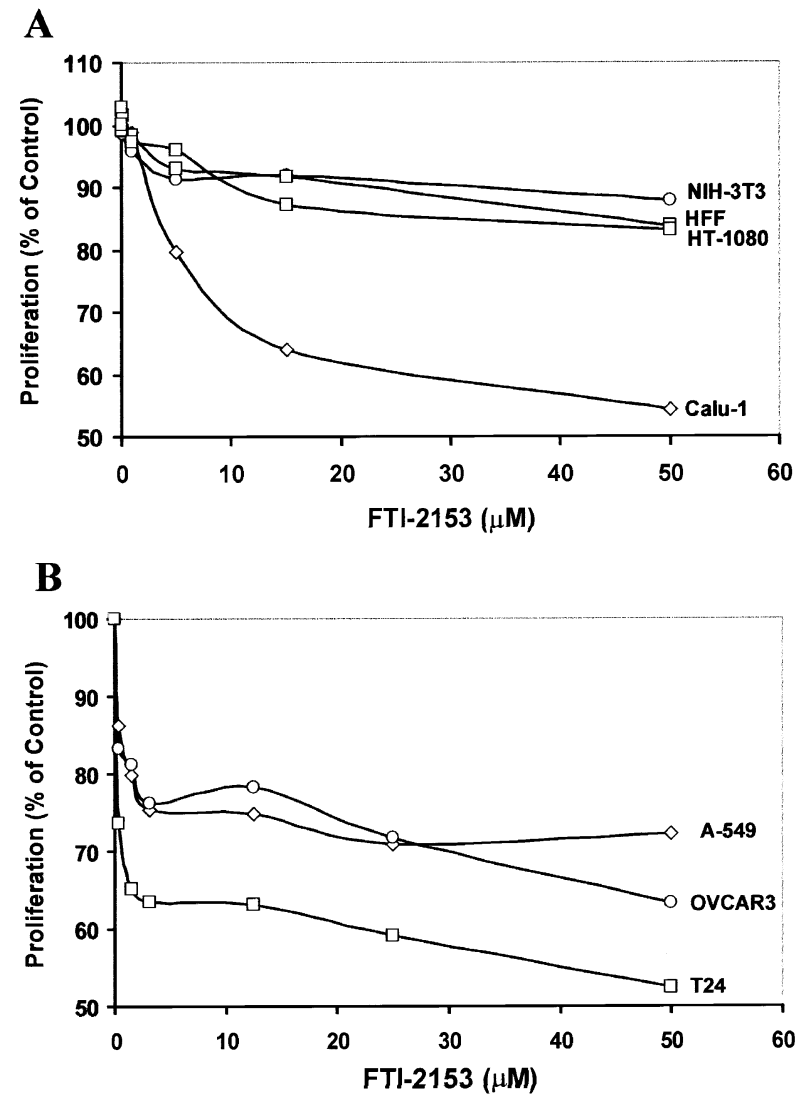

Figure 5 Tumor cell growth inhibition by FTI-2153. Cells were plated in 96well plates and treated with various concentrations of FTI-2153. Inhibition of cell proliferation was determined by MTT assay as described under Materials and Methods immortalized mouse fibroblast cell lines, NIH3T3, we have demonstrated that FTI-2153 inhibits bipolar spindle formation in non-transformed cells (i.e. HFF). This is a highly significant finding that indicates that the farnesylated proteins that mediate prometaphase transition during mitosis are also present in untransformed cells such as the primary foreskin fibroblasts HFF. Furthermore, the tissue of origin is not important since these effects were seen with HT1080 (fibrosarcoma), A-549 and Calu-1 (lung carcinoma), and OVCAR3 (ovarian carcinoma). More importantly, the effects are independent of the Ras mutation status since they were seen in cancer cell lines with both wild-type Ras (OVCAR3) and mutated Ras (A-549 (K-Ras), Calu-1 (K-Ras), and HT1080 (N-Ras)). Similarly, the ability of FTI-2153 to inhibit bipolar spindle formation is independent of the p53 deletion/ mutation status since Calu-1 (deleted p53), OVCAR3 (mutated p53) and HFF, HT1080, A-549 (WT p53) are similarly affected. This is consistent with work published by Ashar et al. ${ }^{22}$ However, FTI-2153 did not inhibit bipolar spindle formation in two cell lines: T-24, a bladder carcinoma with $\mathrm{H}-$ Ras and p53 mutations and NIH3T3 cells with WT Ras and p53. At this stage the mechanism by which these two cell lines escape the FTI effects is not known. Consistent with this data, FTI-2153 does not induce prometaphase accumulation in these cell lines.

Another important finding of our studies is that inhibition of tumor cell proliferation does not require inhibition of bipolar spindle formation. For example the growth of both T-24 and Calu- 1 cells was equally inhibited yet FTI-2153 did not inhibit bipolar spindle formation in T-24 cells. Furthermore, inhibition of bipolar spindle formation is not sufficient to inhibit tumor cell proliferation. For example, HFF cells were resistant to FTI-2153 tumor cell growth inhibition, yet FTI-2153 inhibited bipolar spindle formation in these cells.

The results of this study suggest that at the prophase/ metaphase transition during mitosis, certain farnesylated proteins are required for bipolar spindle formation. The centromere-associated kinetochore protein, CENP-E has been suggested as a candidate farnesylated protein by Ashar et al. ${ }^{22}$ However, we $e^{21}$ and Ashar et al. ${ }^{22}$ have shown that the two structurally distinct FTIs, FTI-2153 and $\mathrm{SCH} 66366$ do not affect the localization of CENP-E to the kinetochore. Furthermore, inhibition of CENP-E function either by microinjecting an antibody against CENP-E or by deleting the CENP-E C-terminus (containing the CAAX sequence) does not result in inhibition of bipolar spindle formation, ${ }^{23-25}$ but rather in inhibition of chromosome alignment at the metaphase plate. Taken together, our results and those of Schaar et al. ${ }^{23}$ suggest that disruption of CENP-E function does not mediate FTI-2153 inhibition of bipolar spindle formation. To date, the mechanism by which FTIs inhibit bipolar spindle formation and accumulate cells in prometaphase is not known. Either a farnesylated protein is directly involved in centrosome separation and bipolar spindle formation, or a farnesylated protein indirectly regulates these processes. A possible candidate is the kinesin-related protein Eg5. Indeed, it has been shown that disruption of Eg5 resulted in cell cycle arrest at mitosis with unseparated spindle poles that were surrounded by a ring 
of chromosomes. ${ }^{26,27}$ Furthermore, Eg5 has been shown to be the target for Monastrol, a compound that was isolated based on its ability to arrest cells in mitosis and that was subsequently shown to inhibit bipolar spindle formation. ${ }^{28}$ However, Eg5 does not contain the farnesylation consensus CAAX motif. Thus, proteins that interact with Eg5 or those involved in its regulation are possible candidates for FTIs.

The inhibition of bipolar spindle formation in the primary HFF cells is intriguing and suggests that farnesylation is required for spindle formation in normal cells. Furthermore, the lack of inhibition of bipolar spindle formation by FTI2153 in T-24 and NIH3T3 cells is also of interest. On treatment with FTls, T-24 cells have been shown to accumulate in the $\mathrm{G} 1$ phase of the cell division cycle. ${ }^{29}$ In these cells a farnesylated protein, possibly mutated $\mathrm{H}$ Ras, is most likely required for the G1/S transition and its inhibition results in $\mathrm{G} 1$ arrest and therefore inhibition of progression to mitosis. Moreover, the absence of any FTI influence on NIH3T3 cell cycle distribution ${ }^{29}$ may also explain the lack of inhibition of bipolar spindle formation. Furthermore, the fact that inhibition of protein farnesylation in NIH3T3 does not result in prometaphase accumulation suggest that establishment of spindle bipolarity in these cells does not require farnesylated proteins.

Taken together, our results demonstrate that the ability of FTIs to inhibit bipolar spindle formation and to accumulate cells in prometaphase during mitosis is not dependent on malignant transformation, or Ras and p53 mutation status. Our data also indicate that, depending on the cell lines, farnesylated proteins are critical at different stages of cell cycle progression and consequently FTIs could inhibit cell growth by mechanisms that involve disruption of cell cycle phases, such as G1 and G2/M.

\section{Materials and Methods}

\section{Cell culture}

OVCAR3 and NIH3T3 cells were maintained in Dulbecco's modified Eagle's medium, HFF and HT1080 cells were maintained in minimum essential medium, A-549 cells were maintained in Kaighn's F12 medium and Calu-1 and T-24 cells were maintained in McCoy's medium. All media were adjusted to contain $1.5 \mathrm{~g} / \mathrm{l}$ sodium bicarbonate and were supplemented with $10 \%$ fetal bovine serum. All cells were grown in a humidified incubator at $37^{\circ} \mathrm{C}$ and $10 \% \mathrm{CO}_{2}$.

\section{Flow Cytometry}

Cells were plated to subconfluency on $100 \mathrm{~mm}^{2}$ plates in order to obtain $5 \times 10^{5}$ to $1 \times 10^{6}$ cells for DNA analysis. Asynchronous cells were treated with either vehicle (DMSO) or $15 \mu \mathrm{M} \mathrm{FTI-2153} \mathrm{for} 72 \mathrm{~h}$. Cells were then harvested with trypsin $(0.05 \%)$ /EDTA $(0.53 \mathrm{mM})$, washed twice with PBS, resuspended in $500 \mu$ of PBS and fixed in $4.5 \mathrm{ml}$ of $70 \%$ ethanol. Cells were stored in ethanol at $-20^{\circ} \mathrm{C}$. When ready to stain with propidium iodide, cells were centrifuged to remove the ethanol and washed once in PBS. The cell pellet was then resuspended in $1 \mathrm{ml} \mathrm{PI/Triton} X-100$ staining solution $(0.1 \%(\mathrm{v} / \mathrm{v})$ Triton X-100 in PBS, $0.2 \mathrm{mg} / \mathrm{ml}$ RNase A and $20 \mu \mathrm{g} / \mathrm{ml}$ propidium iodide) and incubated at room temperature for at least $30 \mathrm{~min}$. DNA analysis was performed using a FACScan flow cytometer (Becton Dickinson, San Jose, CA, USA) and ModFit LT 2.0 (Verity Software House, Topsham, ME, USA).

\section{Immunocytochemistry}

Cells were grown on 2-well Lab-Tek II chamber slides (Nunc, Inc., Naperville, IL, USA) to subconfluency and treated as described above. The cells were fixed in $4 \%$ paraformaldehyde (diluted with PBS from $16 \%$ stock (Electron Microscopy Sciences, Fort Washington, PA, USA)) in a humidified chamber for $20 \mathrm{~min}$ at $4^{\circ} \mathrm{C}$ and permeabilized with $0.5 \%$ Triton $X-100$ in PBS for $1 \mathrm{~h}$. For microtubule immunocytochemistry, the fixed cells were stained with $\alpha$-tubulin ((clone B-5-12), Sigma T5168) diluted in $0.1 \%$ Tween-20, 1\% BSA in PBS for $1 \mathrm{~h}$ and FITC-conjugated goat anti-mouse (Sigma F9006) diluted in $0.1 \%$ Tween-20, 1\% BSA in PBS for 25 min in the dark. After final washes, slides were mounted with VECTASHIELD ${ }^{\mathbb{R}}$ mounting medium with DAPI (Vector Laboratories, Inc., Burlingame, CA, USA) and viewed at $\times 400$ magnification with an Orthoplan 2 fluorescent microscope (Leitz) and SmartCapture VP software (Digital Scientific).

\section{MTT assay}

Cell growth was measured by MTT [3-(4,5-methylthiazol-2-yl)-2,5diphenyltetrazolium bromide] assay. ${ }^{30}$ Briefly, cells were seeded at $1-4 \times 10^{3}$ cells per well in 96 -well culture plates in quadruplicate. The following day, the medium was changed to DMEM supplemented with $10 \%$ FBS containing increasing concentrations of FTI-2153 or DMSO as vehicle. Cells were treated once more with the drugs in the next $48 \mathrm{~h}$. Subsequently, the medium was removed and the cells were incubated with $100 \mu \mathrm{l}$ of DMEM containing $10 \% \mathrm{FBS}$ and $0.25 \mathrm{mg} / \mathrm{ml}$ MTT (Sigma) at $37^{\circ} \mathrm{C}$ for $3 \mathrm{~h}$, followed by solubilization with DMSO for $10 \mathrm{~min}$. The absorbance of each well was measured with a microplate reader at $570 \mathrm{~nm}$. The number of viable cells is proportional to the absorbance.

\section{Acknowledgements}

We thank Ms. Jodi Kroeger for her help with flow cytometry analysis. This work was supported in part by the National Cancer Institute grant \#CA67771 (SM Sebti and AD Hamilton). The work was also supported in part by the Flow Cytometry, Pathology and Molecular Imaging cores at the H. Lee Moffitt Cancer Center and Research Institute.

\section{References}

1. Zhang FL and Casey PJ (1996) Protein prenylation: molecular mechanisms and functional consequences. Annu. Rev. Biochem. 65: 241-269

2. Sebti SM and Hamilton AD (2000) Farnesyltransferase and geranylgeranyltransferase I inhibitors and cancer therapy: Lessons from mechanism and bench-to-bedside translational studies. Oncogene 19: 6584-6593

3. Gibbs JB and Oliff A (1997) The potential of farnesyltransferase inhibitors as cancer chemotherapeutics. Annu. Rev. Pharmacol. Toxicol. 37: 143-166

4. Cox AD and Der CJ (1997) Farnesyltransferase inhibitors and cancer treatment: targeting simply Ras? Biochim. Biophys. Acta 1333: F51-F71

5. James GL, Goldstein JL, Brown MS, Rawson TE, Somers TC, McDowell RS, Crowley CW, Lucas BK, Levinson AD and Marsters Jr JC (1993) Benzodiazepine peptidomimetics: potent inhibitors of Ras farnesylation in animal cells [see comments]. Science 260: 1937-1942 
6. KohI NE, Mosser SD, deSolms SJ, GiulianiEA, Pompliano DL, Graham SL, Smith RL, Scolnick EM, Oliff A and Gibbs JB (1993) Selective inhibition of rasdependent transformation by a farnesyltransferase inhibitor [see comments]. Science 260: $1934-1937$

7. Sun J, Qian Y, Hamilton AD and Sebti SM (1998) Both farnesyltransferase and geranylgeranyltransferase I inhibitors are required for inhibition of oncogenic $\mathrm{K}$ Ras prenylation but each alone is sufficient to suppress human tumor growth in nude mouse xenografts. Oncogene 16: 1467-1473

8. Pollack IF, Bredel M, Erff M, Hamilton AD and Sebti SM (1999) Inhibition of Ras and related guanosine triphosphate-dependent proteins as a therapeutic strategy for blocking malignant glioma growth: II-preclinical studies in a nude mouse model. Neurosurgery 45: 1208-1214; discussion 1214-1215

9. Sepp-Lorenzino L, MaZ, Rands E, KohI NE, Gibbs JB, Oliff A and Rosen N (1995) A peptidomimetic inhibitor of farnesyl:protein transferase blocks the anchoragedependent and -independent growth of human tumor cell lines. Cancer Res. 55: $5302-5309$

10. Kohl NE, Wilson FR, Mosser SD, Giuliani E, deSolms SJ, Conner MW, Anthony NJ, Holtz WJ, Gomez RP, Lee T-J, Smith RL, Graham SL, Hartman GD, Gibbs JB and Oliff A (1994) Protein farnesyltransferase inhibitors block the growth of rasdependent tumors in nude mice. Proc. Natl. Acad. Sci. USA. 91: 9141-9145

11. Liu M, Bryant MS, Chen J, Lee S, Yaremko B, Lipari P, Malkowski M, Ferrari E, Nielsen L, Prioli N, Dell J, Sinha D, Syed J, Korfmacher WA, Nomeir AA, Lin CC, Wang L, Taveras AG, Doll RJ, Njoroge FG, Mallams AK, Remiszewski S, Catino JJ, Girijavrallabhan VM and Bishop WR (1998) Antitumor activity of SCH 66336, an orally bioavailable tricyclic inhibitor of farnesyl protein transferase, in human tumor xenograft models and wap-ras transgenic mice. Cancer Res. 58: 49474956

12. Hunt JT, Ding CZ, Batorsky R, Bednarz M, Bhide R, Cho Y, Chong S, Chao S, Gullo-Brown J, Guo P, Kim SH, Lee FY, Leftheris K, Miller A, Mitt T, Patel M, PenhallowBA, Ricca C, Rose WC, Schmidt R, SlusarchykWA, Vite G and Manne V (2000) Discovery of (R)-7-cyano-2,3,4, 5-tetrahydro-1-(1 H-imidazol-4ylmethyl)-3-(phenylmethyl)-4-(2-thienylsulfonyl)-1H-1,4-benzodiazepine (BMS-214662), a farnesyltransferase inhibitor with potent preclinical antitumor activity. J. Med. Chem. 43: 3587-3595

13. Nagasu T, Yoshimatsu K, Rowell C, Lewis MD and Garcia AM (1995) Inhibition of human tumor xenograft growth by treatment with the farnesyl transferase inhibitor B956. Cancer Res. 55: 5310-5314

14. Kohl NE, Omer CA, Conner MW, Anthony NJ, Davide JP, deSolms SJ, Giuliani EA, Gomez RP, Graham SL, Hamilton K, HandtLK, Hartman GD, Koblan KS, Kral AM, Miller PJ, Mosser SD, O'Neill TJ, Rands E, Schaber MD, Gibbs JB and Oliff A (1995) Inhibition of farnesyltransferase induces regression of mammary and salivary carcinomas in ras transgenic mice [see comments]. Nat. Med. 1: 792797

15. Barrington RE, Subler MA, Rands E, Omer CA, Miller PJ, Hundley JE, Koester SK, Troyer DA, Bearss DJ, Connor MW, Gibbs JB, Hamilton K, Koblan KS, Mosser SD, O'Neill TJ, Schaber MD, SenderakET, Windle JJ, Oliff A and KohI NE (1998) A farnesyltransferase inhibitor induces tumor regression in transgenic mice harboring multiple oncogenic mutations by mediating alterations in both cell cycle control and apoptosis. Mol. Cell. Biol. 18: 85-92

16. Mangues R, CorralT, KohI NE, Symmans WF, LuS, Malumbres M, Gibbs JB, Oliff A and Pellicer A (1998) Antitumor effect of a farnesyl protein transferase inhibitor in mammary and lymphoid tumors overexpressing $\mathrm{N}$-ras in transgenic mice. Cancer Res. 58: 1253-1259
17. Omer CA, Chen Z, Diehl RE, Conner MW, Chen HY, Trumbauer ME, GopalTruter S, Seeburger G, Bhimnathwala H, Abrams MT, Davide JP, Ellis MS, Gibbs JB, Greenberg I, Koblan KS, Kral AM, Liu D, Lobell RB, Miller PJ, Mosser SD, O'Neill TJ, Rands E, Schaber MD, Senderak ET, Oliff A and Kohl NE (2000) Mouse mammary tumor virus-Ki-rasB transgenic mice develop mammary carcinomas that can be growth-inhibited by a farnesyl:protein transferase inhibitor. Cancer Res. 60: 2680-2688

18. Sebti SM and Hamilton AD (2000) Farnesyltransferase and geranylgeranyltransferase I inhibitors in cancer therapy: important mechanistic and bench to bedside issues. Expert Opin. Invest. Drugs 9: 2767-2782

19. Rowinsky EK, Windle JJ and Von Hoff DD (1999) Ras protein farnesyltransferase: A strategic target for anticancer therapeutic development. J. Clin. Oncol. 17: $3631-3652$

20. Vogt A, Qian Y, McGuire TF, Hamilton AD and Sebti SM (1996) Protein geranylgeranylation, not farnesylation, is required for the $\mathrm{G} 1$ to $S$ phase transition in mouse fibroblasts. Oncogene 13: 1991-1999

21. Crespo NC, Ohkanda J, Yen TJ, Hamilton AD and Sebti SM (2001) The farnesyltransferase inhibitor, FTI-2153, blocks bipolar spindle formation and chromosome alignment and causes prometaphase accumulation during mitosis of human lung cancer cells. J. Biol. Chem. 276: 16161-16167

22. Ashar HR, James L, Gray K, Carr D, Black S, Armstrong L, Bishop WR and Kirschmeier $\mathrm{P}(2000)$ Farnesyl transferase inhibitors block the farnesylation of CENP-E and CENP-F and alter the association of CENP-E with the microtubules. J. Biol. Chem. 275: 30451-30457

23. Schaar BT, Chan GK, Maddox P, Salmon ED and Yen TJ (1997) CENP-E function at kinetochores is essential for chromosomealignment. J. Cell. Biol. 139: $1373-1382$

24. Chan GK, Schaar BT and Yen TJ (1998) Characterization of the kinetochore binding domain of CENP-E reveals interactions with the kinetochore proteins CENP-F and hBUBR1. J. Cell. Biol. 143: 49-63

25. Wood KW, Sakowicz R, Goldstein LS and Cleveland DW (1997) CENP-E is a plus end-directed kinetochore motor required for metaphase chromosome alignment. Cell 91: 357-366

26. Vaisberg EA, Koonce MP and McIntosh JR (1993) Cytoplasmic dynein plays a role in mammalian mitotic spindle formation. J. Cell. Biol. 123: 849-858

27. Blangy A, Lane HA, d'Herin P, Harper M, Kress M and Nigg EA (1995) Phosphorylation by p34cdc2 regulates spindle association of human Eg5, a kinesin-related motor essential for bipolar spindle formation in vivo. Cell 83: $1159-1169$

28. Mayer TU, Kapoor TM, Haggarty SJ, King RW, Schreiber SL and Mitchison TJ (1999) Small molecule inhibitor of mitotic spindle bipolarity identified in a phenotype-based screen. Science 286: 971-974

29. Vogt A, Sun J, Qian Y, Hamilton AD and Sebti SM (1997) The geranylgeranyltransferase-I inhibitor GGTI-298 arrests human tumor cells in G0/G1 and induces p21(WAF1/CIP1/SDI1) in a p53-independent manner. J. Biol. Chem. 272: 27224-27229

30. Carmichael J, DeGraff WG, Gazdar AF, Minna JD and Mitchell JB (1987) Evaluation of a tetrazolium-based semiautomated colorimetric assay: assessment of chemosensitivity testing. Cancer Res. 47: 936-942 